\title{
IMPACT OF NOCTURNAL NATURAL VENTILATION ON THE ENERGY CONSUMPTION OF BUILDINGS
}

Felicia UCIU - PhD Student, Technical University of Civil Engineering Bucharest, e-mail: feliciauciu@gmail.com Tiberiu CATALINA - Associate Professor, PhD, Technical University of Civil Engineering Bucharest, Faculty of Building Services

Andreea VARTIRES - Associate Professor, PhD, Technical University of Civil Engineering Bucharest, Faculty of Building Services

Iolanda COLDA - Professor, PhD, Technical University of Civil Engineering Bucharest, Faculty of Building Services

\begin{abstract}
The analysis presented in this paper is dealing with the correct and energy efficient measures of cooling buildings through nocturnal natural ventilation. Using this solution is proved in this article to be efficient and can reduce substantially the cooling demand.

In order to establish the factors influencing the process of passively cooling a building (the ventilation volume, exterior temperature, thermal capacity of the building, possible duration of the ventilation), we have chosen different buildings, which we have placed them in different temperature zones of Romania. The study is based on multiple simulations realized with a time step of one hour, with the following variations: the climatic parameters, the thermal characteristics of the building, the air flow during night time, the proposed interior temperature. Since the study consisted of numerous simulations, in order to treat the results we have used statistical methods that cover the practical and possible situations, and proved the efficiency of nocturnal ventilation.
\end{abstract}

Keywords: ventilation, natural nocturnal cooling, indoor air temperature, energy consumption.

\section{Introduction}

The actual world energy context is defined by multiple energy challenges and asks for a common effort in order to reduce the energy consumption through the inteligent conception and use of buildings. The phenomena specific to modern civilization, in their advance towards progress, produce damaging effects on our life and future. The decizions we take on a global and personal level are very important for the protection of our future. The increase in population, combined with the demand to increase the living standards lead to significant energy consumptions. Continuing to use traditional energy production methods, will lead to severe greenshouse effect. The present paper has the scope to show, through case studies, the influence energy consumption, specifically the use of energy for cooling. We have include in the study parametric data on air flows, ventilation strategies, building structure type, building floor position and climate date. "People spend $90 \%$ of their time in enclosed spaces, and breathe $30 \mathrm{~kg}$ of aer each day. Why, how much, and how do we ventilate?” [1]. These are the problems that renowned specialists propose for a new research. The method of building cooling through nocturnal ventilation is recently considered, on an international level, as being second to shading, a technical solution to make buildings more efficient from an energetic perspective [2].

Under the authority of the Executive Committee to Conserve Building Energy belonging to AIE, and the Comunitary Program AIE ECBCS, the „EBC Annex 62 Ventilative Cooling” has been created [3]. "Annex 62" has meant four years of work and reports, during 2014-2017, Venticool being a key communication partner. In this context there have been talks about the strategies to 
cool interior spaces, about challenges and solutions, about using interior air to reduce the energy consumption [4]. We will mark a few of the conclusions to the presented research:

- For a certain location, the night cooling techniques' cooling potential depends on the air flow [5], building's thermal capacity, and the corresponding coupling of the thermal mass and air flow;

- Individual reactions vis-a vis buildings with air conditioning should be further investigated, since many people opt for the comfort associated with natural ventilation [6];

- Maximum interior temperature is a function of the exchange rate of the night ventilation air, thermal mass and the temperature difference in residencial buildings [7];

- The effect of working parameters: by increasing the thermal mass through exchanging construction materials (from $887 \mathrm{~kg} / \mathrm{m}^{2}$ to $1568 \mathrm{~kg} / \mathrm{m}^{2}$ ), a significant reduction of interior temperature has been obtained, around $2-3^{\circ} \mathrm{C}$. The increase of ventilation rates $>10$ exchanges/hour has not led to a significant improvement [8]. The efficiency of massive walls, with regard to storing thermal energy in structural materials in the outside envelope of the building [9]. The use of phase shifting materials (PCM) to renovate a high school built in 1961, a building with a low thermal inertia [10].

Cooling through ventilation using the exterior air with a temperature lower than the predicted one has two temporal aspects:

1. $\mathrm{DAY}=$ the interior of the building is ventilated, at the requirements for air quality

2. NIGHT = the mass of the building is cooled due to a lower temperature of exterior air.

Circulating cool air during night through the building dissipates the stored heat from the day. According to the thermal capacity of the exposed mass, the cooling load can be reduced if these gains can be stored and released as necessary. In order to track the phenomena and its performances we have simulated nocturnal ventilation in different buildings.

In order to assess the benefits of night ventilation, the KoZiBu software is used for this purpose. It is based on the thermo-electric analogy that represents the basis of theoretical modeling of thermo-aeraulic phenomena in buildings. This can analyze the dynamic hydrothermal performance of construction elements when they are subjected to any type of weather conditions. The main objective of the software is to estimate the energy consumption, and the variation of the temperature interval. The KoZiBu software allows to estimate the cooling energy necessary in order to maintain a certain comfort set temperature [11], or to compute the free interior temperature. The software is based on modeling a thermal system composed of a building placed in the exterior environment. This system is made out of elementary modules (walls, windows, air volumes, etc), for which a model is realized. The connection between these modules represents the global model of the building. External factors (external climate, interior loads, etc) are applied to this model. The dynamic behavior of the building is deduced from the fact that the software keeps track of the time variable characteristics of these factors; the output data are computed according to the time step chosen. In this case it is an hour. The BESTEST validation software ensures the reliability of the simulations with experimental data. The physical model of the $\mathrm{KoZiBu}$ software is based on the scenario that every volume of air contains temperature controllers (heating/cooling), or humidity controllers, with their own power and position. In their absence, the adjustment of the temperature and humidity evolves freely. The building is described through a graphical interface, with a tree similar to that of Windows Explorer. The entry data are the elements that define the building (building geometry, air volumes, walls, windows with or without solar protection).The wall data are the layers (materials and thickness), azimuth, inclination, etc. 
The main parameters modeled in our simulation study are:

- Internal loads (heat generated by lights, personnel, machines, etc);

- Building structure and materials;

- Regulators (set power and temperature, humidity, ventilation);

- Weather with the following information - position of the Sun (azimuth and altitude), air temperature, solar flow (direct and diffuse).

The output data, in a graphical form, are couples of values and time that give results for viewing and printing purposes. With these graphs we have compared alternatives selected to provide information with regard to energy consumption.

\section{Data inputs for the simulation study}

Structuring the objective of the analysis, the energy savings for cooling and the gathering of data required to evaluate the potential of natural nocturnal cooling were aimed at the building zones most affected by this problem more exactly the highest requirements in the cooling season. The analysis of summer temperatures in representative locations for the climate subareas in Romania have shown that in the southern region the thermal comfort raises energy requirements and surpassed the climate norm by $4^{0} \mathrm{C}$. Summer begins with the month of May and ends in the middle of September in the southern plains. In this area of Romania there are more than 40 "tropical" days (with temperatures that surpass $30^{\circ} \mathrm{C}$ ) and over 90 days of Summer (with temperatures over $25^{0} \mathrm{C}$ ) [12].

We have simulated nocturnal ventilation for various types of buildings (structural differences), placed differently (geographically) in real climate conditions for the year 2012, in the months of June, July, August, September, based on a set schedule.

In table 1 we can observe the locations and geographical coordinates for which we generated the weather database.

Table 1

Geographical positions simulated in the KOZIBU software

\begin{tabular}{|c|c|c|}
\hline Craiova & Bucharest & Constanta \\
\hline Latitude: $44.3 \mathrm{~N}$, longitude: & Latitude: $44.5 \mathrm{~N}$, longitude: & Latitude: $44.22 \mathrm{~N}$, longitude: \\
23.8E, altitude: $192 \mathrm{~m}$ & $26.13 \mathrm{E}$, altitude: $90 \mathrm{~m}$ & 28.63E, altitude: $13 \mathrm{~m}$ \\
\hline
\end{tabular}

We have one by one made simulations for two situations: an office situated on the ground floor and on the last floor in a building with external wall insulated GVP masonry. The simulated buildings had two types of roofs (attic or terrace). The windows are double glazed types PVC and the glazing ratio is $10 \%$ from the floor area.

The building we have studied $(\mathrm{GF}+3)$ has the following dimensions: $\mathrm{BxLxH}=14.6 \mathrm{x} 33 \mathrm{x} 10.50 \mathrm{~m}$. The office has the plane dimensions $6 \mathrm{~m} \times 30 \mathrm{~m}=180 \mathrm{~m}^{2}$ and a height of $3 \mathrm{~m}$. The interior volume is $540 \mathrm{~m}^{3}$. The office benefits from natural light, due to its 8 windows that are oriented to the South. For data pertaining to the position of the Sun (solar azimut, solar height), and the intensity of direct an diffuse Solar radiation specific to each analysed location, we have used specialized websites that contain these data [13]. All of these have halped in computing the solar flow.

There are 40 people working in the office and the occupancy schedule is 8-18 h (Monday, Tuesday, Wednesday, Thursday, Friday, and at the end of the week it is closed). The simulated building receives natural sunlight thanks to the windows placed on the southern side of the 
building. There are no other internal sources of heat except the humans. During the working period the office building is ventilated with 1.5 ach (air change rate to volume) to maintain a good air quality. The nocturnal ventilation scenario followed throughout the simulations is based on increasing the ventilation rate from 2, 3, 4 ach during the night.

\section{Results}

The output data, the couples [values, time] have been utilized to prepare the graphs that will put into perspective alternatives regarding energy consumption necessary for the proposed scenario (the building has nocturnal ventilation with the ventilation rate of 2, 3 or 4 ach). To exemplify the variation of consumption as a function of outdoor temperature, the increase of the rate of nocturnal ventilation and the structure of the building (ex. Ground floor/top floor), we present the cooling consumption for the month of August 2012, the $2^{\text {nd }}$ and $3^{\text {rd }}$ weeks, Bucharest, ground floor office (see Fig. 1) and top floor office under a terrace (see Fig. 2).

Table 2

Average temperatures day/night, August 2012, Bucharest

\begin{tabular}{|c|c|c|c|c|}
\hline Week & Week1 & Week2 & Week3 & Week4 \\
\hline $\mathrm{t}_{\text {med day }}\left[{ }^{0} \mathrm{C}\right]$ & 30.5 & 23.7 & 30.2 & 24.3 \\
\hline $\mathrm{t}_{\text {med night }}\left[{ }^{0} \mathrm{C}\right]$ & 24.4 & 17 & 21.1 & 17.46 \\
\hline
\end{tabular}

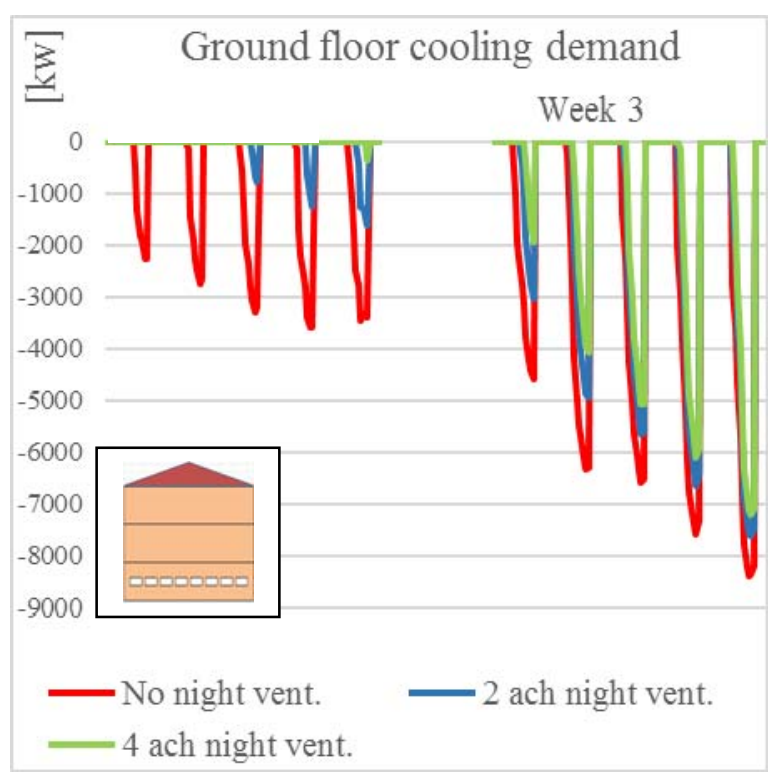

Fig.1 - Cooling demand - office top floor, Air set point $=25^{\circ} \mathrm{C}$

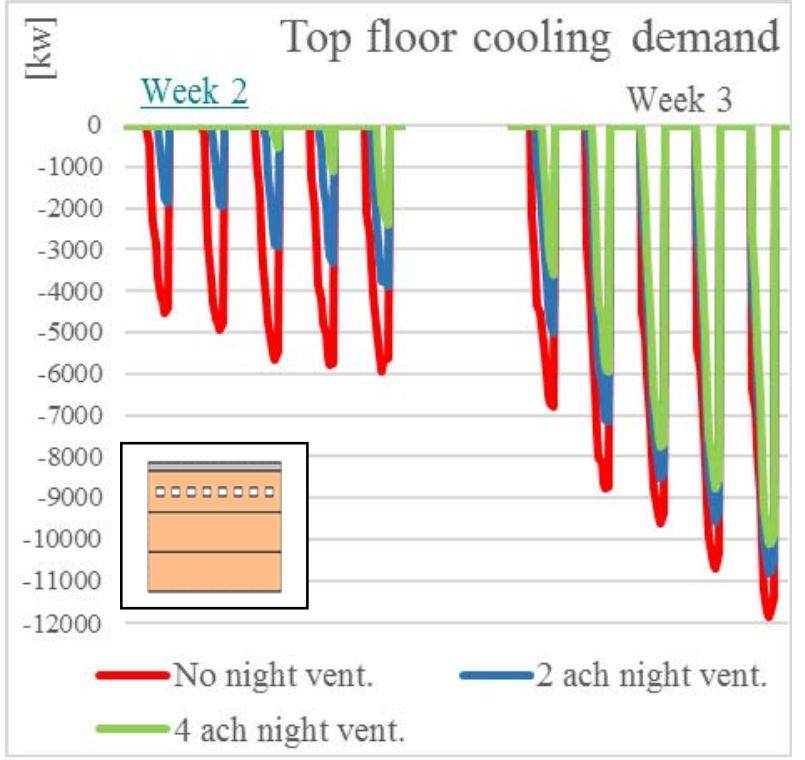

Fig.2 - Cooling demand - office top floor, Air set point $=25^{\circ} \mathrm{C}$

The more the nocturnal temperature drops below $18^{0} \mathrm{C}$ the more the differences are less evident.

By modifying the indoor air temperature by $0.5^{\circ} \mathrm{C}$ we raise consumption for cooling by $24 \%$. We relate to the case where indoor set point temperature proposed is $25^{\circ} \mathrm{C}$ and we present the percentage growth in consumption for the ground floor office, in the hypothesis in which we propose for indoor air temperature to $24^{\circ} \mathrm{C}$ and $24.5^{\circ} \mathrm{C}$ and the case for cooling with nocturnal ventilation at nocturnal ventilation rates of 2, 3, 4 ach, (fig. 3), (no=short for nocturnal). Reporting will be done for the interior temperature of $25^{\circ} \mathrm{C}$. 


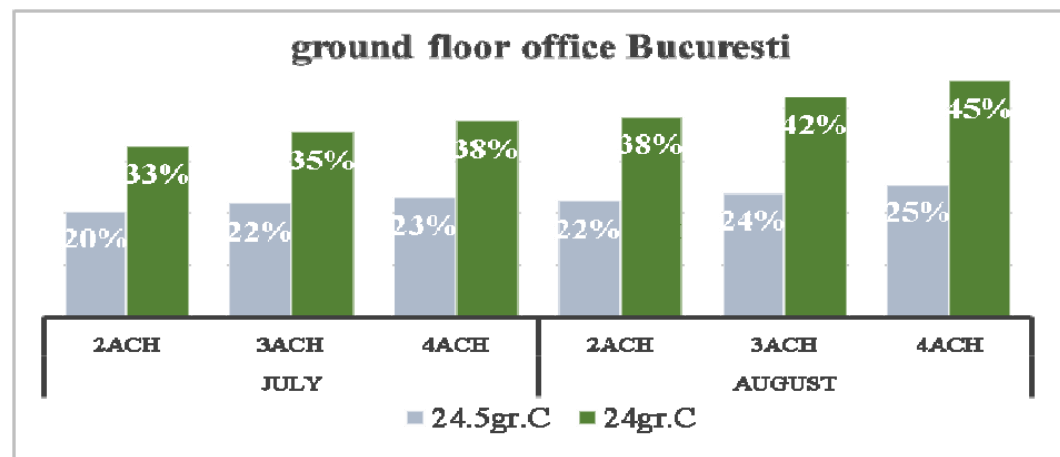

Fig. 3 - Extra energy consumption for cooling with nocturnal ventilation for air set point temperature of $24^{0} \mathrm{C}$ and $24.5^{\circ} \mathrm{C}$ in relation to consumption at for air set point temperature at $25^{\circ} \mathrm{C}$

By processing the graphic data revealed following the simulations for the proposed scenarios, the energy values necessary for cooling, when the rate of ventilation during the night was increased from 2 ach to 4 ach in the time period 19:00-08:00, were decreased by $26 \%$ in July and $40 \%$ in August (fig.4).

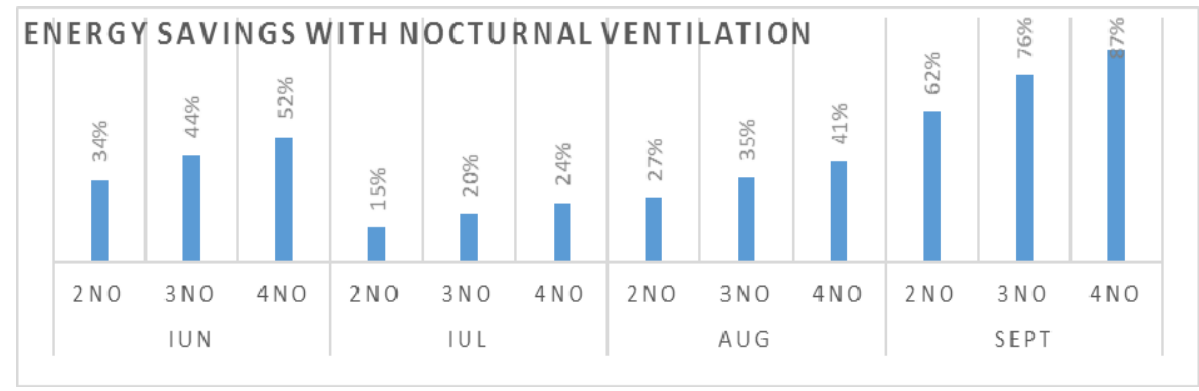

Fig. 4 - Percentage reduction of required cooling by applying nocturnal ventilation to a top floor office for a set point of 250C, with nocturnal ventilation in relation to the situation without nocturnal ventilation

While analyzing the variation of energy consumption for cooling, regardless of the geographic location/position the nocturnal ventilation method has proved its efficiency at nocturnal temperatures under $18^{0} \mathrm{C}$ and every building based on its structure has seen improvements based on its specific conditions. In fig. 5 we exemplify for Bucharest year 2012, for the other cities the ratio $\mathrm{kWh} /$ building and rate of nocturnal ventilation is almost the same.

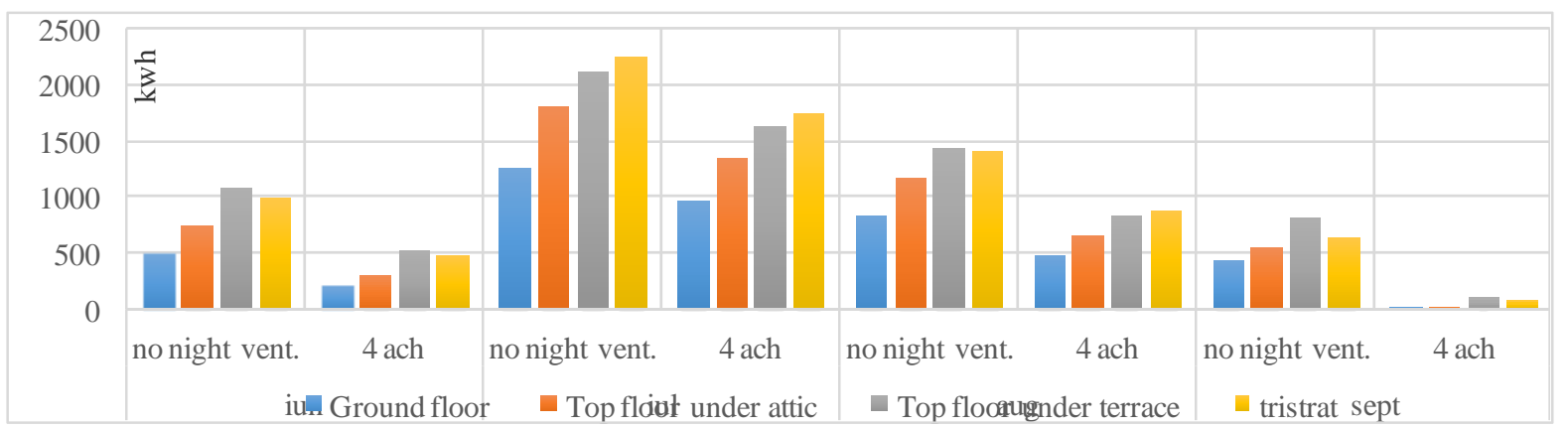

Fig. 5- Cooling demand in kWh based on the envelopment of the building with nocturnal ventilation (4 ach) and without nocturnal ventilation, $t$ int proposed $=25^{\circ} \mathrm{C}$

The results obtained have shown that each structure has its own response to the charges to which it is subjected. Let us consider the two cases, without nocturnal ventilation and with nocturnal ventilation regardless of the zone (ground or top floor) (fig. 6) for the whole cooling season. On the $\mathrm{X}$ axis we recorded the consumption value for cooling without nocturnal ventilation. The difference between the two representation, fig. 6 is given by the structure. In the case where the solar radiation charges directly the terrace the weekly values are constantly higher by $50 \mathrm{kWh}$. 

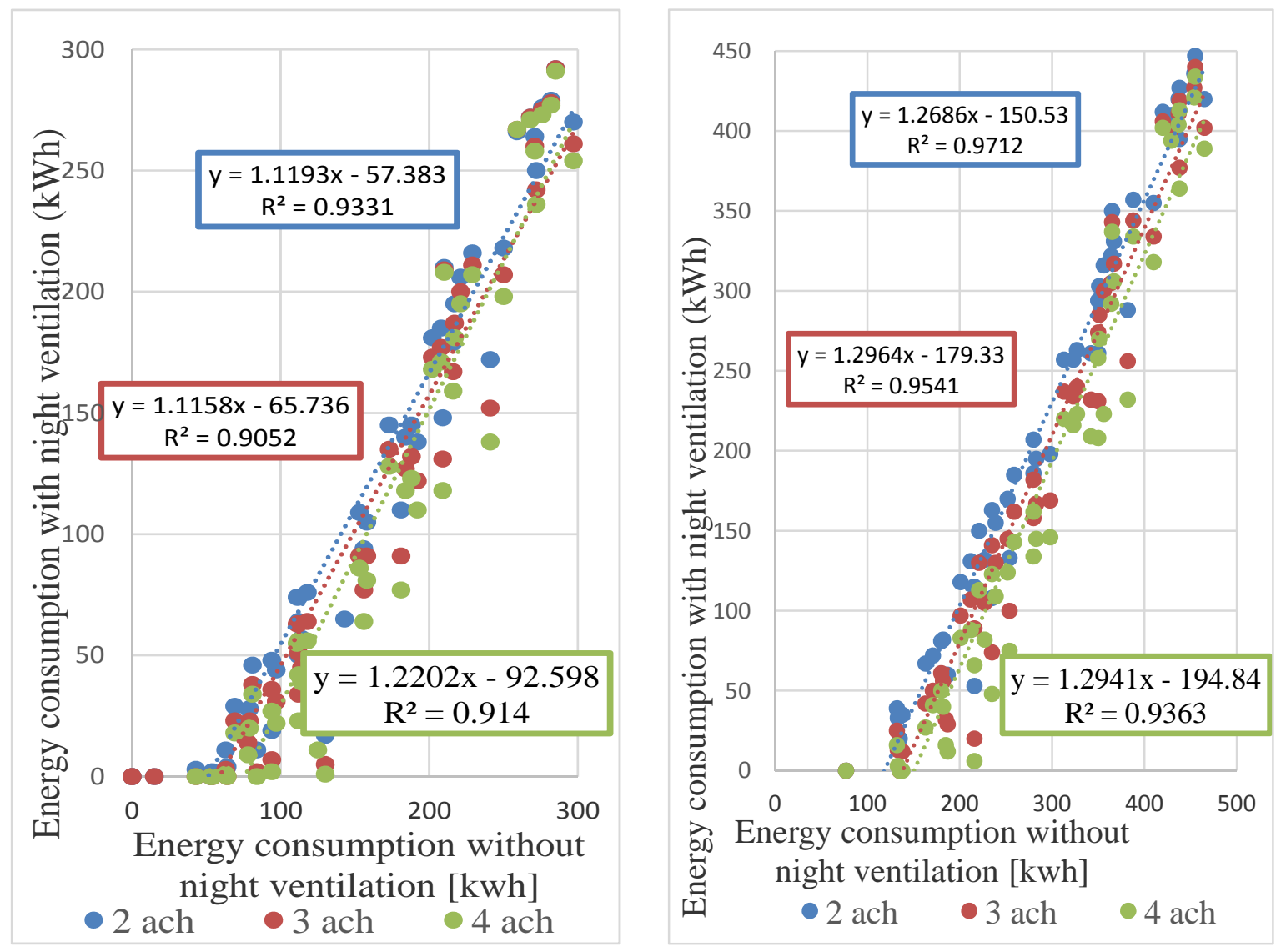

a

Fig. 6 - Cooling energy consumption relation with and without nocturnal ventilation for various types of structures (ground - Fig. 6a and top floor - Fig. 6b)

The results interpretation has shown that in each location (identical climate conditions) the envelopment of the building, the indoor air temperature proposed and the rate of ventilation are the parameters which define the cooling consumption. The lower nocturnal temperatures at ground level help building on the ground to save energy for cooling - the attic of the building is very important; the temperature graph shows that it has kept the cool air from previous days, maintaining the building towards the equilibrium temperature, after a longer period (two weeks) of higher temperatures (during the day $>27-28^{\circ} \mathrm{C}$ ), until the average exterior temperature drops down to $24^{\circ} \mathrm{C}$, $\left(34^{\circ} \mathrm{C}\right.$ during the day and $14^{\circ} \mathrm{C}$ at night). Fig. 7 presents the efficiency of the method as a percentage for the types of buildings analized. As we have shown the first term that qualifies the cooling method through nocturnal ventilation as a second method of passive cooling after shading is the nocturnal temperature.

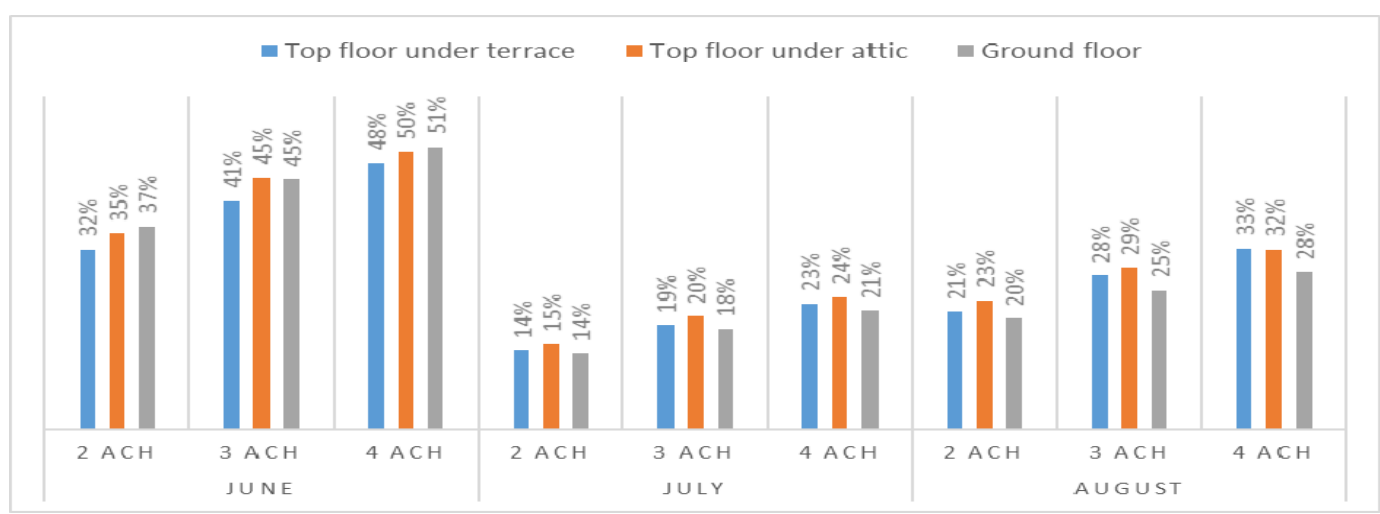

Fig. 7- Cooling energy reduction when applying nocturnal ventilation in relation to the situation without nocturnal ventilation 
Looking at a summary of this study we can observe that the highest efficiency has been recorded in Bucharest because of the lower noctunral temperatures (see Fig.8). Craiova is representative for the hot plains climate, and Constanta even though the temperatures are somewhat managed by the sea breze, the nights are still very hot.

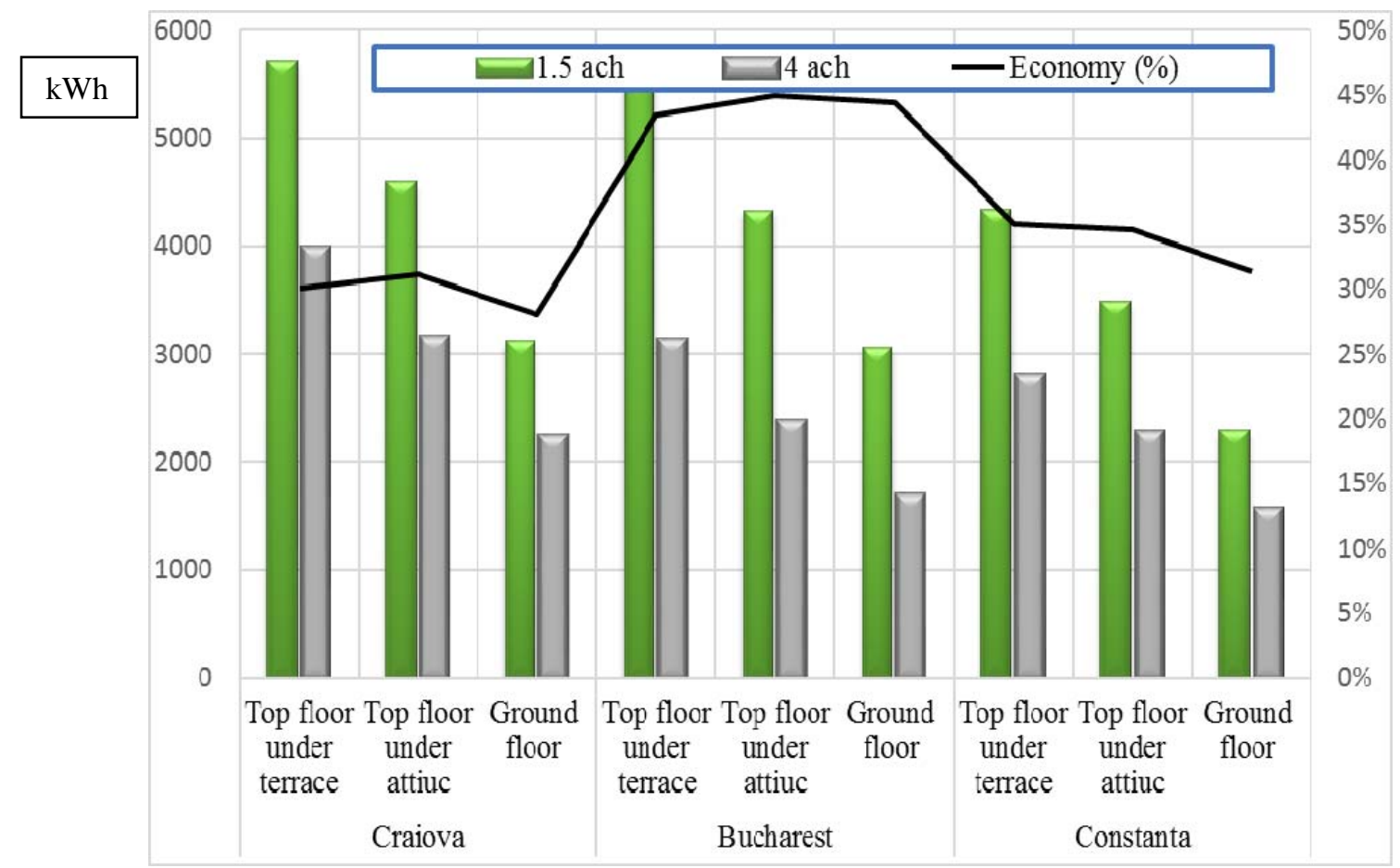

Fig. 8 - Energy consumption for cooling and economy for different climates, different position in the building and for different night ventilation rates

In fig. 8 we outline the centralization of energy consumption for cooling for each type of building for different location in the summer season 2012. The curve (black line) indicates the percentage savings by applying nocturnal ventilation. By following the graphical reprezentation of the corelation between the external temperature and the energy consumption for cooling in each case where the rate of nocturnal ventilation has been 2 ach, 3 ach, 4 ach we can observe the same relation which defines the corelation for a rate and a structure. To exemplify we discuss on the case nocturnal ventilation (4 ach) in fig.8.

Table 3

Correlation relation (t night_consumption for cooling) for different structures and locations

\begin{tabular}{|c|c|c|c|c|c|c|c|c|}
\hline $\begin{array}{l}\text { Consumption [kWh] } \\
=\mathrm{f}(\mathrm{t} \text { night })\end{array}$ & City & Craiova & Bucharest & Constanta & Average & \multicolumn{3}{|c|}{ Error } \\
\hline \multirow{3}{*}{ Ground floor } & $X$ & 27.747 & 27.655 & 29.441 & 28.281 & \multirow[t]{3}{*}{$2 \%$} & \multirow[t]{3}{*}{$2 \%$} & \multirow[t]{3}{*}{$-4 \%$} \\
\hline & free & -489.23 & -459.73 & -521.01 & -489.99 & & & \\
\hline & $\mathrm{R}^{2}$ & 0.861 & 0.8742 & 0.8695 & 0.86823 & & & \\
\hline \multirow{3}{*}{ Attic } & $\mathrm{X}$ & 37.466 & 38.171 & 39.761 & 38.466 & \multirow[t]{3}{*}{$3 \%$} & \multirow[t]{3}{*}{$1 \%$} & \multirow[t]{3}{*}{$-3 \%$} \\
\hline & free & -654.36 & -629.38 & -696.71 & -660.15 & & & \\
\hline & $\mathrm{R}^{2}$ & 0.8824 & 0.8889 & 0.8976 & 0.88963 & & & \\
\hline \multirow{3}{*}{ Terrace } & $\mathrm{X}$ & 39.387 & 41.937 & 44.423 & 41.9157 & \multirow[t]{3}{*}{$6 \%$} & \multirow[t]{3}{*}{$0 \%$} & \multirow[t]{3}{*}{$-6 \%$} \\
\hline & free & -663.35 & -675.93 & -766.34 & -701.87 & & & \\
\hline & $\mathrm{R}^{2}$ & 0.8801 & 0.9289 & 0.9292 & 0.91273 & & & \\
\hline
\end{tabular}


In table 3 for each type of structure we follow the relation t ext night in relation with the consumption for cooling. For this type of linear corelation with the corelation coeficient $\left(R^{2}>0.86\right)$, the relation is $\mathrm{Y}=\mathrm{a} \mathrm{X}+\mathrm{b}$, where $\mathrm{Y}$ is the consumption, $\mathrm{a}$ the slope and $\mathrm{b}$ the free term, which shows how $\mathrm{Y}$ grows to the variation of $\mathrm{X}$ (here the average night temperature).

$\begin{array}{llll}\begin{array}{l}\text { Ground floor } \\ \text { Top floor } \\ \text { under attic }\end{array} & \mathrm{kWh}=\mathrm{t}_{\text {night }} \cdot 28.281-489.99 & (1), \mathrm{Y}=0=>\mathrm{t}_{\text {average_night }}=17.32^{\circ} \mathrm{C} \\ \begin{array}{l}\text { Top floor } \\ \text { under terrace }\end{array} & \mathrm{kWh}=\mathrm{t}_{\text {night }} \cdot 38.466-660.15 & \text { (2) } & \mathrm{t}_{\text {average_attic }}=17.16^{0} \mathrm{C} \\ & \mathrm{kWh}=\mathrm{t}_{\text {night }} \cdot 41.9157-701.87 & \text { (3) } & \mathrm{t}_{\text {average_terrace }}=16.74^{0} \mathrm{C}\end{array}$

For each type of structure we wrote the corelation relation. Our interest is to have consumption $Y$ $[\mathrm{kWh}]=0$. We impose this condition in $(1,2,3,4)$ and obtain the average night temperature for which the aplication of the nocturnal ventilation method has an efficiency of $100 \%$.
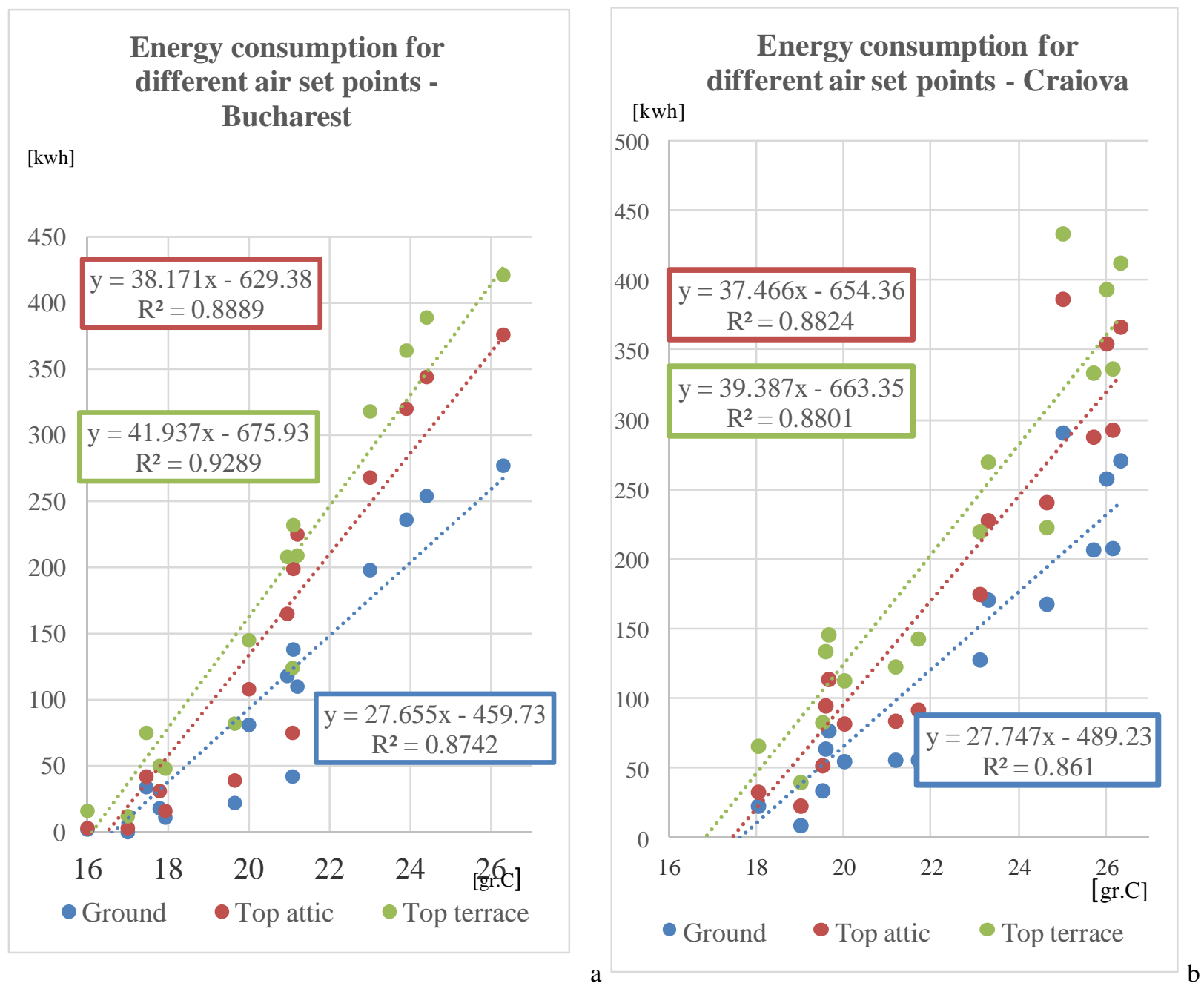

Fig. 9 - Energy consumption for different air set points (ground - Fig. 9a and top floor - Fig. 9b) 


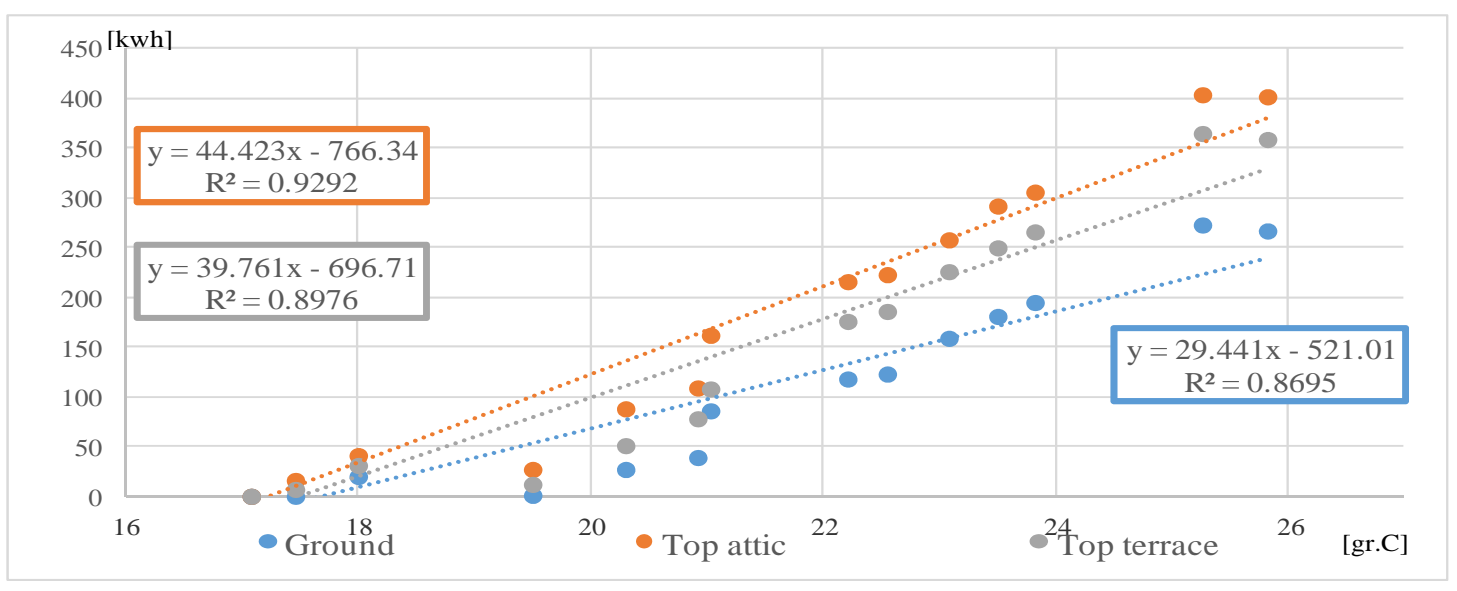

Fig. 10 - Relationship between the indoor day air temperature and the energy consumption for Constanta climate at nocturnal air change rate of 4 ach

We can observe the same phenomenon in the case in which we relate to the day temperature (fig. 10,11).

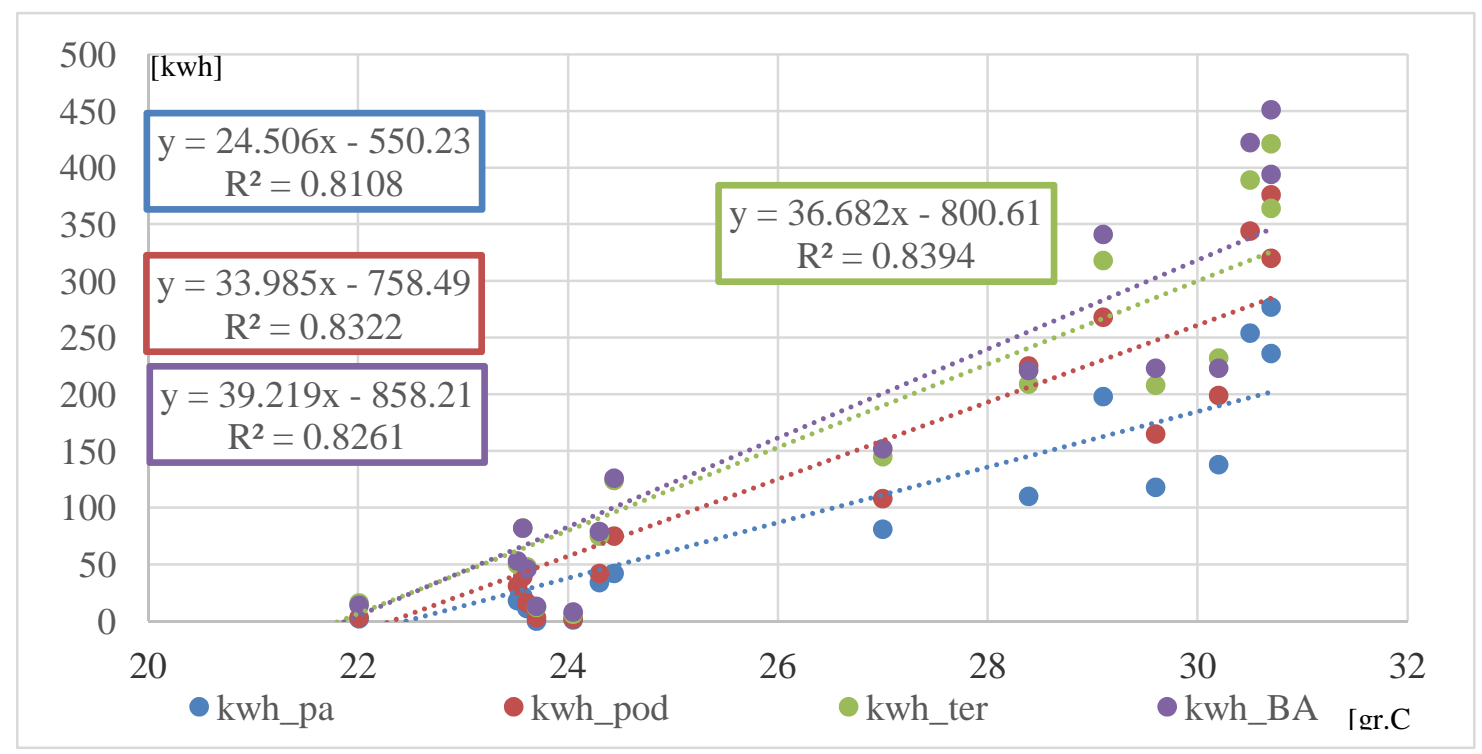

Fig. 11 - Relationship between the indoor day air temperature and the energy consumption for Bucharest climate at nocturnal air change rate of $\mathrm{VN}=4$ ach

Table 4

Correlation relation between day temperature set point and for different structures and locations

\begin{tabular}{|c|c|c|c|c|c|c|c|c|}
\hline Consumption = & City & Bucharest & Craiova & Constanta & Average & \multicolumn{3}{|c|}{ Error } \\
\hline \multirow{3}{*}{ Ground floor } & $\mathrm{x}$ & 24.506 & 28.50 & 27.464 & 26.824 & \multirow[t]{3}{*}{$9 \%$} & \multirow[t]{3}{*}{$6 \%$} & \multirow[t]{3}{*}{$2 \%$} \\
\hline & free & -550.23 & -614.6 & -623.72 & -596.19 & & & \\
\hline & $\mathrm{R}^{2}$ & 0.8108 & 0.857 & 0.8196 & 0.8294 & & & \\
\hline \multirow{3}{*}{ Attic } & $\mathrm{x}$ & 33.985 & 38.27 & 37.29 & 36.516 & \multirow[t]{3}{*}{$7 \%$} & \multirow[t]{3}{*}{$5 \%$} & \multirow[t]{3}{*}{$2 \%$} \\
\hline & free & -758.49 & -818.1 & -840.7 & -805.7 & & & \\
\hline & $\mathrm{R}^{2}$ & 0.8322 & 0.869 & 0.8553 & 0.852 & & & \\
\hline \multirow{3}{*}{ Terrace } & $\mathrm{x}$ & 36.682 & 39.95 & 41.714 & 39.449 & \multirow[t]{3}{*}{$7 \%$} & \multirow[t]{3}{*}{$1 \%$} & \multirow[t]{3}{*}{$6 \%$} \\
\hline & free & -800.61 & -828.1 & -928.5 & -852.4 & & & \\
\hline & $\mathrm{R}^{2}$ & 0.839 & 0.855 & 0.8874 & 0.860 & & & \\
\hline
\end{tabular}


Table 4 resumes the corelation relations, consumption/outdoor day temperature and we can observe that deviations of up to $10 \%$ can appear which increases the fiability in establishing a corelation average night temperature/energy consumption.

\section{Conclusions}

Choosing the interior temperature during working hours brings important variations in the energy consumption for cooling. Lowering the internal temperature with $0,5^{\circ} \mathrm{C}$ leads to a increasing of the reqired energy consumption for cooling with $25-45 \%$.

Increasing the number of air flows in natural nocturnal cooling to 4 ach leads to lowering the energy consumption for cooling by $26 \%$ for the month of July, and $40 \%$ for the month of August, in contrast to the solution without nocturnal cooling. We can observe the tendency to save energy by applying nocturnal ventilation on the office situated on the last floor, the percentage being much smaller due to the influence of solar radiation.

For the city of Constanta, the geographical location on the seaside is beneficial, tempering the maximum values, in comparrison to the continental area of Dobrogea, even though the temperatures are stil high. An office located on the Ground Floor where 40 people do their work might benefit from the application of nocturnal ventilation during summer, with the exception of the month of July, if the manager of the building can apply this solution.

The variance of energy consumption for cooling is based on the climate region, characterized by temperature, radiation, the rate of nocturnal ventilation, the structure of the building and the internal proposed air temperature. The high number of simulations proves the efficiency of the nocturnal ventilation technique even in very warm regions or for torid periods; the transition periods are the ones for which the energy benefits are the most significant $\quad$ (50-100\%). We have found significat differences between ground floor and top floor in terms of cooling demand. It was also notice a reduction by $45 \%$ for Bucharest climate if we use 4 ach night ventilation.

\section{References}

[1] Colda, I. (2014). Ventilarea si consumul de energie. Energy Performance of Buildings. Bucuresti, from http://www.aiiro.ro.

[2] Ralf Cavelius, I. (2014). Passive Cooling. Viena: Austrian Energy Agency, from http://citeseerx.ist.psu.edu.

[3] IEA-EBC project annex 62. (2012), from www.iea-ebc.org, http://www.iea-ebc.org/projects/ongoingprojects/ebc-annex-62/

[4] IEA EBC. (2017). Feedback from the IEA. Venticool the international platform for ventilative cooling, The Executive Committee of the IEA Energy in Buildings and Communities programme, Newsletter no.9.

[5] Kolokotsa, M. S. (2013). Passive cooling dissipation techniques for buildings and other structures: The state of the art. 1st venticool Conference, 25-26 September 2013, Athens, from http://www.aivc.org/resource/passivecooling-dissipation-techniques-buildings-and-other-structures-state-art.

[6] Hassid, S. (2013). Individual appreciation of air conditioned surroundings. 1st venticool Conference, p. 3rd TightVent. 25-26 September 2013, Athens, 74.1367313206.

[7] Edna Shaviv, A. (2001). Thermal mass and night ventilation as passive cooling design strategy. Renewable Energy.

[8] Finn, D. (2005). Sensitivity analysis of a maritime located night ventilated library building. International Conference "Passive and Low Energy Cooling for the Built Environment", Santorini, Greece.

[9] Akbari, H. D. (1986). The effect of variations in convection coefficients on thermal energy storage in buildings Part I - Interior partition walls. Energy and Buildings.

[10] Virgone, J. N. (2009). Numerical study of the influence of the thickness and melting point on the effectiveness of phase change materials:application to the renovation of a low inertia school. Eleventh International IBPSA Conference, Building Simulation. Glasgow, Scotland.

[11] KoZiBu - Simulation Dynamique d'un Bâtiment, from http://www.jnlog.com/kozibu1_fr.htm

[12] Administratia Nationala de Meteorologie, (2016). Scenarii climatice, from http://www.meteoromania.ro/.

[13] Sun Position. (2012). From http://www.sunearthtools.com.

[14] Bucuresti. (2012), from https://www.wunderground.com/ro/ 